\title{
HBIM FOR ARCHAEOLOGICAL SITES: FROM SFM BASED SURVEY TO ALGORITHMIC MODELING
}

\author{
V. Bagnolo ${ }^{1, *}$, R. Argiolas ${ }^{1}$, A. Cuccu ${ }^{1}$ \\ ${ }^{1}$ DICAAR, University of Cagliari, Faculty of Engineering and Architecture, Cagliari (CA), Italy \\ vbagnolo@unica.it; raffaele.argiolas@hotmail.com; alessandro.cuccu3@gmail.com
}

\section{Commission II}

KEY WORDS: HBIM, SfM, Algorithmic modelling, Ionic colonnade, Temple of Antas, Sardinia

\begin{abstract}
:
The implementation of new technologies often leads research towards experimentation with new methodological approaches. The BIM process applied in cultural heritage is increasingly consolidating its practices, expanding its potential even in the field of archaeological research. Integrating archaeological data into BIM models has clear benefits but, due to the complexity of the involved elements, archaeological case studies can fit effectively into the BIM process only with the creation of semantic-aware libraries implementing dedicated objects. Cultural heritage can advantage of BIM-based knowledge management only integrating approaches and tools with different characteristics from those commonly used in BIM workflows. In the phase of the geometric modeling process, following that of the survey process and preparatory to the subsequent information modeling process, when the detected geometries are not easily traceable to libraries of pre-compiled objects, an alternative to the so-called "Scan to BIM" local modeling can be represented by algorithmic modeling. The paper, focusing on the geometric modelling phase of the HBIM process, presents first results and prospective tasks of an ongoing research project on the last architectural phase of the colonnade of a multilayered temple in the Antas valley in Sardinia (Italy), affected by imposing works of anastylosis and restoration.
\end{abstract}

\section{INTRODUCTION}

\subsection{Geometric modeling process: modeling options in HBIM environment}

The Historic Building Information Modelling (HBIM) is increasingly consolidating its practices, expanding its potential even in the field of archaeological research (Garagnani el al., 2016). New technologies applied to cultural heritage offer rich research fronts but often do not fully reveal its potential when technology is used without involving a review of the consolidated processes, designed and developed in different work contexts and for other purposes. In cultural heritage, the introduction of the BIM methodology imposes a revision of the processes that characterize the approach both in the architectural and in the archaeological survey.

Although archaeological data are increasingly integrated into BIM workflows, processes do not always define optimal conditions that can summarize the knowledge of different disciplinary sectors. One of the issues on which it may be useful to investigate is certainly that relating to the semantic modeling for archaeology. To find effective application, the BIM process must be able to express itself through a correct and effective modeling process.

In construction, the digital model is the exact digital equivalent of the structure to be built. The different disciplines involved in the project can converge into models that are the product of a conscious aggregation of elements each endowed with their own "intelligence", in order to allow the different values to relate to each other within precise rules.

The procedure typically used in HBIM can be schematised in two main phases: the geometric modeling process and the subsequent information modeling process. We will focus on the first phase, that of the survey and of the geometric modeling. Especially when dealing with complex construction elements BIM for heritage uses is often based on a geometric modelling commonly referred to the so-called "Scan to BIM" process, made possible today thanks to the constant progress in data capture skills and software.

In general, it would be good practice, when possible, to construct object libraries by tracing back the geometry of point clouds to simplified geometries, in order to obtain effective models to which data can be associated. Unfortunately, this process is not always feasible as often the detected geometries are not easily traceable to libraries of pre-compiled objects. In this case, a local modeling is often used.

This paper deals with the question of geometric modeling by investigating how, depending on the geometry of the various components, different models can be used. Starting from the generation of point clouds, in the case of certain elements characterized by complex geometries, we can use, as appropriate, the algorithmic modeling as an effective alternative to the local modeling process, typically used in the so-called "scan to BIM" processes.

The research paper proposal is about the effectiveness of the BIM methodology applied to an archaeological site, especially in relation to the procedural modeling practices useful to historic elements. Furthermore, the purpose of the study was also to acquire data to verify a detailed knowledge of the architectural order used to rebuild the site. Starting from the need for documentation of existing assets, survey and digitalization process of the different instances in historic buildings or archaeological sites involves a review of the traditional modeling techniques, as polygonal models or NURBS surfaces, not so effective in BIM environment.

* Corresponding author 


\subsection{Why algorithmic modeling?}

In HBIM process, trying to combine the BIM methodology with the issues related to built heritage, two major problems are linked to the automation of the segmentation of point clouds and to the creation of reusable parametric complex objects.

It is indeed in these two directions that most of the published research work on HBIM is addressed. If the automatic recognition of the different parts of point clouds and their management still has uneven tools, giving really usable results only in references to very simple geometries such as walls and floors, the parametric modeling, developed in fields other than BIM, enjoys today very advanced tools that can remedy the shortcomings of the BIM platforms. This is why in the BIM environment for the geometric modeling processes it is customary to use more advanced "external" tools that allow the management of the models to be imported later into BIM software.

In the last few years, however, in an increasingly integrated way, the BIM methodologies include algorithmic modeling tools, which allow greater flexibility in modeling and managing the generative parameters of the geometries (Figure 1). It is therefore a matter of creating partially parametric objects, still bound to some limits set by the development environments, but through an algorithmic process that is in turn parametric; an approach of this kind, different at a conceptual level compared to normal practice, allows us to overcome many of the limitations that normally make the development of HBIM libraries difficult, requiring them to reproduce complex objects. Moreover, since the whole process takes place within the BIM environment, most of the compatibility problems in the import phases are eliminated; if in fact it is true that there are standard formats (IFC) for the exchange of data, the most important BIM software use proprietary formats that do not lend themselves to real interoperability. Once generated, objects can be used as any parametric object and enriched with additional information either with classical methods or by using Dynamo definitions again.

\section{HBIM WORKFLOWS IN ARCHEOLOGY}

Although it may seem that the combination of BIM and archaeological heritage could be used mainly for documentation, a brief summary of the actual literature shows that this field is already quite developed and many interesting applications of BIM for archaeological heritage have already been implemented. The studies show that BIM can be used both for documentation and for the project of temporary structures for the conservation or virtual reconstructions.

Augmented Reality is one of the topics frequently addressed in the BIM environment for archeology. An example is given by the study about the virtual reconstruction of the ancient Etruscan city Kainua, today's Marzabotto, carried out by the University of Bologna in order to create a virtual model of the entire town and making it explorable through Augmented Realty (Garagnani et al. 2016a, 2016b). While being an important part of the study, Augmented Reality is not the only objective. The virtual representation of the city is also an experimental way to investigate a site by integrating different actors and knowledge. The central BIM model would then provide a solid database where all choices regarding the virtual reconstruction of buildings can be verified and argumented. The same nature of BIM softwares provides a paradigmatic change in representation: whereas in a CAD drawing the model is just a geometric construction, in the modelling space of a BIM software, it is important every element represents an object that exists both in 3D and 2D space. This characteristic makes easier and more efficient every verification of the model and lets the user create the building following the same logic used in architectural construction. Semantic modeling plays a central role in this study, with every object being related to semantic information and therefore making the model a sort of "visual index of contents", a three-dimensional database of archaeological information.

Another interesting example of BIM application for archaeological documentation is represented by the modelling of Castor and Pollux Temple in Cori, Italy (Parello et al., 2014). This model, created by a research group from the Sapienza University in Rome, has been built creating a complex system of ontologies and hierarchies. While not being a reconstruction of the ideal state of the temple, this model shows all the phases of the site, starting from its creation until the most recent conservation campaigns. Among the possibilities given by using BIM processes for archaeological heritage, one uncommon but useful practice is the one that consists in using BIM to build a model of the devices used in order to guarantee, even temporarily, the conservation and/or the accessibility of the site (Simeone et al., 2014).

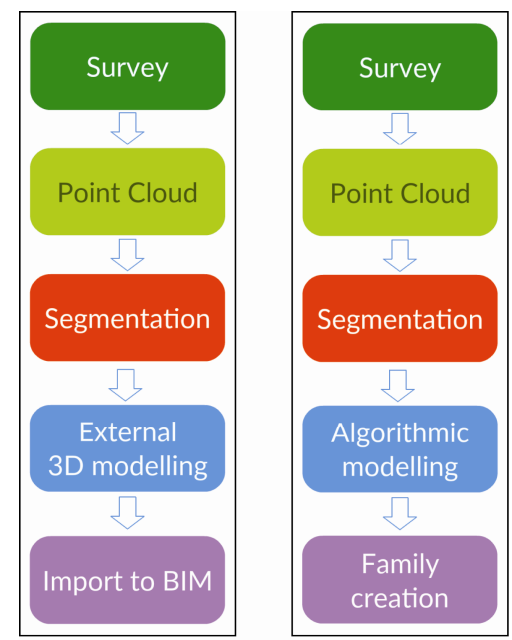

Figure 1. A comparison between the two considered geometric modeling processes in HBIM: local modeling on the left, algorithmic modeling on the right

\subsection{The geometric modeling process}

The SfM based survey process has become consolidated in the practice of the HBIM methodology in order to populate the semantic-aware library of architectural elements (Santagati et al., 2016). In the transition from point cloud to object parametrization, the main methodology, now consolidated and analyzed in numerous case studies from the scientific literature, consists of three fundamental phases: the segmentation of the point cloud according to what emerged from the study phase with possible hierarchization of the sub-components and their study, identification of profiles and sections on which to base the modeling and finally the actual modeling.

The segmentation phase, to be carried out manually in most cases, involves the identification of the individual objects to be modelled and is today one of the most time-consuming phases and requires a thorough knowledge of the elements (Grilli et al., 2017). Knowledge that is also essential in the phase of extrapolation of profiles and sections as these, in almost all 
cases, follow formal and proportional rules precise and documented by the treatises. The profiles thus obtained are the starting point for modeling the various components that make up the object under study.

Given the complexity that certain objects can achieve, often their modeling requires tools that go far beyond the flexibility offered by BIM environments. It is now common practice to rely on specific modeling software for creating 3D models; once the models have been created, they are then imported into the BIM environment, where the objects are parameterized and all the data that make up the knowledge about that element are entered. In the case in which the object is particularly complex or represents a unique case, another solution can be that of directly inserting a mesh surface obtained from the point cloud. Studying classical architecture, geometric analysis can trace back to the original design language (Migliari, 1991). In the process of analyzing architectural patterns, drawing presupposes and provides an accurate reading that translates into graphical means definitions and rules of architecture, emphasizing the key features of geometric modeling.

The proportionment procedures of the architectural orders reflect a disciplined array within a unitary system, providing a very useful key even in virtual reconstruction processes (Apollonio et al., 2012. Bartzis, 2017).

The survey of the colonnade of the temple of Antas provides the occasion to recap the principles and rules holding the conception and construction of architectural orders. The check made on the coherence of the proportions identified in the survey of the columns with the compositional harmonies involved in architectural orders, has allowed to identify the principles on which to base the geometric modeling of the individual components.

\section{CASE STUDY: THE COLONNADE OF THE TEMPLE OF ANTAS}

The ancient Punic-Roman temple of Sardus Pater Babai, known as the "Temple of Antas" from the name of the valley in which it stands, is located in the mountainous central-southern Sardinia region of Iglesias, within the territory of the municipality of Fluminimaggiore (SU) (Figure 2).

Mentioned in the first editions of Ptolemy's Geography circulating in Sardinia in the 16th century, the "Sardopátoros ieròn" was unknown to the Sardinians until then. The rediscovery of the ancient toponym aroused the public's curiosity and stimulated intellectuals' interest to track down the site. Aimed at the search for the lost city at first and at the reconstruction of the temple later, the Sardus Pater site investigations constituted one of the most fascinating questions of ancient topography in Sardinia (Zucca, 1989).

During his wanderings in Sardinia, intent on the execution of topographic surveys for the drafting of the "Carta dell'Isola e Regno di Sardegna" and the compilation of his "Voyage en Sardigne", Alberto Della Marmora gives us a first representation of the ruined temple (Figure 3).

In 1839, on behalf of Alberto della Marmora, Gaetano Cima carried out an architectural survey of the temple and designed a reconstruction proposal. Taking up again the hypothesis put forward by Gaetano Cima, imposing works of anastilosis, promoted by the superintendent archaeologist Ferruccio Barreca, was completed in 1976 (Barreca, 1975; Barreca 1985; Zucca, 1989; Ganga et al., 2013).

In the reconstruction, the building rests on an elevated plateau with a front staircase. Longitudinally tripartite, the plan of the temple is articulated in a pronaos, a cell and a bipartite adyton.
Despite the absence of unequivocal archaeological data, the hypothesis advanced in the temple reconstruction is still today accepted without substantial modifications (Bernardini, Ibba 2015).

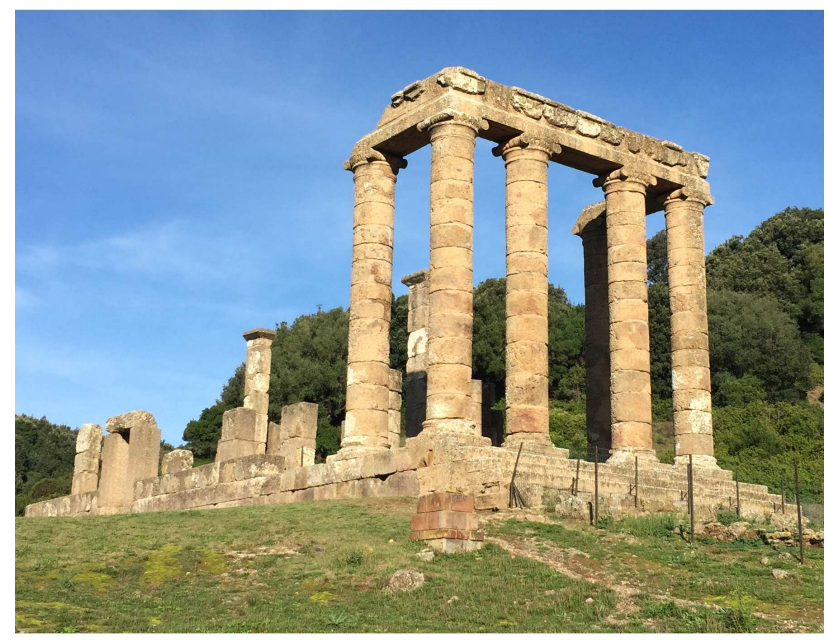

Figure 2. The pronaos of the temple of Antas (Fluminimaggiore, $\mathrm{SU})$.

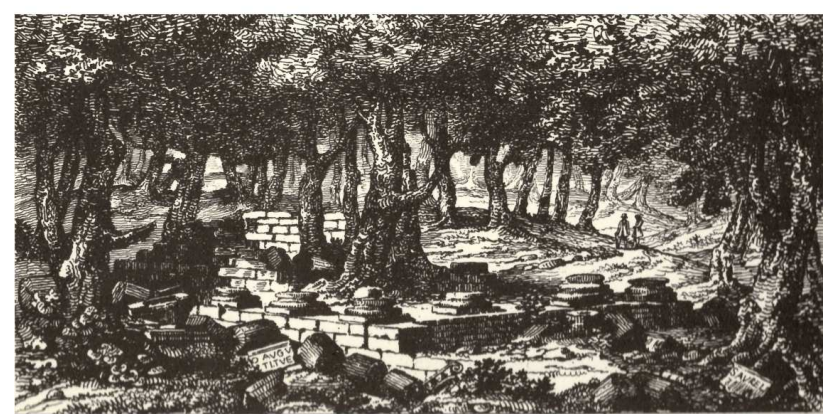

Figure 3. The ruins of the temple of Antas seen by Alberto della Marmora in the nineteenth century (della Marmora, 1840).

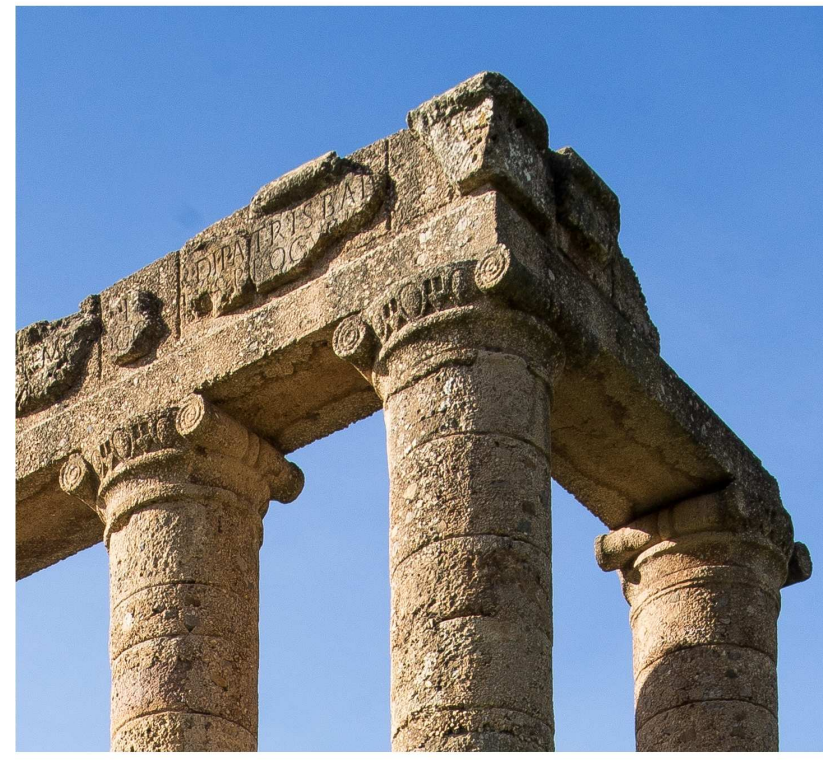

Figure 4. Detail on the three Ionic capitals of the southeast corner of the pronaos 
In the first steps of the research, our attention has been turned to the colonnade in the pronaos of the temple, where six columns with Ionic capitals surmounted by an entablature stand on a base of stacked disks of clastic rocks. A defining pair of small volutes decorates each capital, enriched with an echino carved with an egg-and-dart ornament.

\subsection{D data acquisition}

In the analysis of the archaeological site of Antas, the peculiarities related to the process of geometric modeling of the "column" component led us to identify the pronaos as the first part to consider in our research.
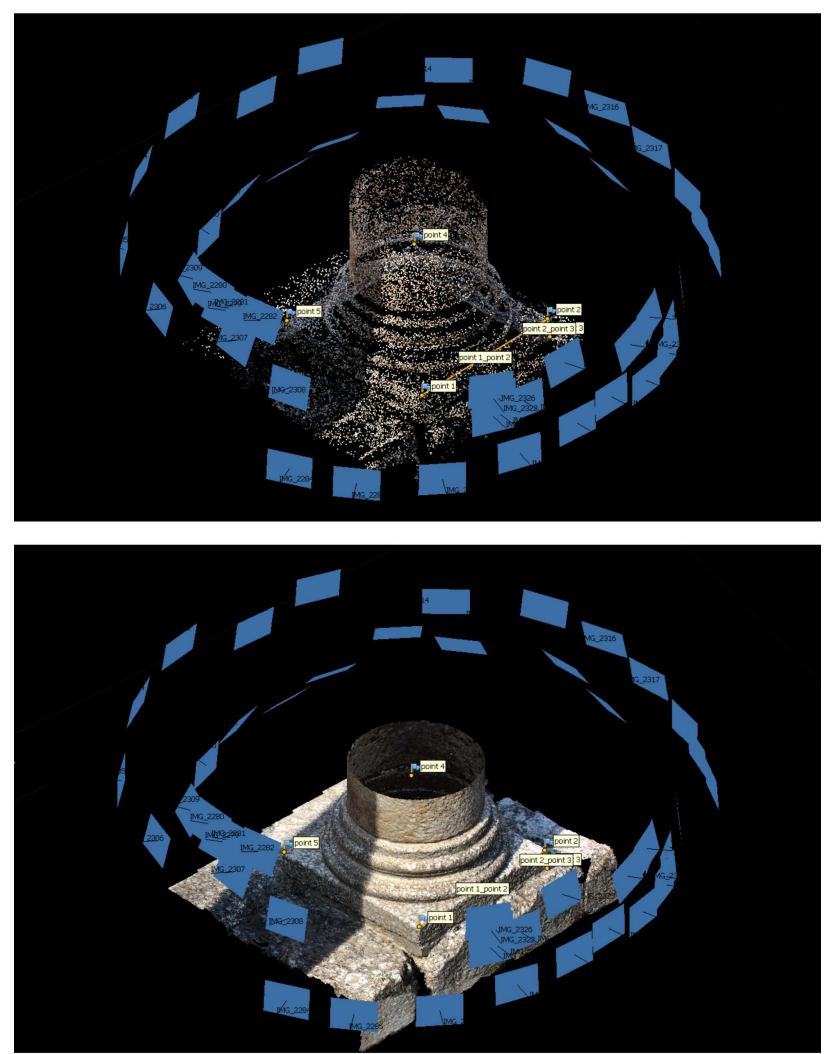

Figure 5. Photomodeling of the plinth and of the Attic base of the column: the alignment process in the point clouds and in the mesh model.

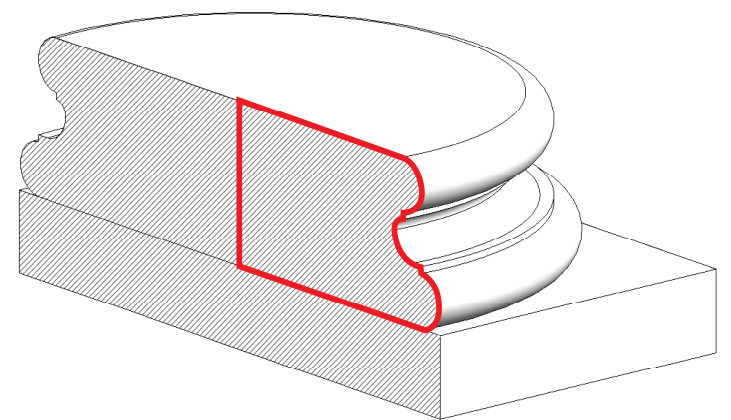

Figure 6 . The profile used for the generation of the parametric model of the Attic base of the temple of Antas.
The colonnade of the temple of Antas consists of six columns circumscribing the portico, surmounted by an entablature (Figure 4).

The six columns have an Ionic capital and Attic base resting on a plinth above the stylobate. The current arrangement of this part of the temple it's the result of the restoration of each single component of the architectural order first, and of a subsequent anastylosis of colonnade and entablature then.

The field survey covered the six Ionic columns using Structure from Motion (SfM) photogrammetric technology. The measurement operations were carried out with a Nikon NPL 350 no prism total station with a sensitivity threshold of $\pm 5 \mathrm{cc}$. The digital camera is a Nikon D3300 with a resolution of 6000 pixels x 4000 pixels, a focal length of $18 \mathrm{~mm}$, sensor dimensions of $23.5 \mathrm{~mm} \times 15.6 \mathrm{~mm}$ and a pixel size of 3.92 microns. The photogrammetric processing of digital images and generation of 3D spatial data, have been performed using the commercial software Agisoft Photoscan that, compared with other tecniques such as Terrestrial Laser Scanning (TLS), achieves very high performance and accuracy (Chiabrando et al., 2017; Remondino et al., 2014).

Starting from the generation of 3D point clouds from image sequences (Figure 5), the aim was to create a 3D model of each column in which registered survey data could be converted into objects able to be managed in a BIM environment.

\subsection{D modeling}

Geometric modeling is set up to define the different modeling processes that better perform the discretization of each single component according to its complexity and to the necessary simplification of the complex geometries required in the BIM environment for process efficiency. The codification of the treatises on architectural orders constituted the principle on which both phases of the restitution of the survey and of the parametrization of the components in the $3 \mathrm{D}$ modeling have been hinged.

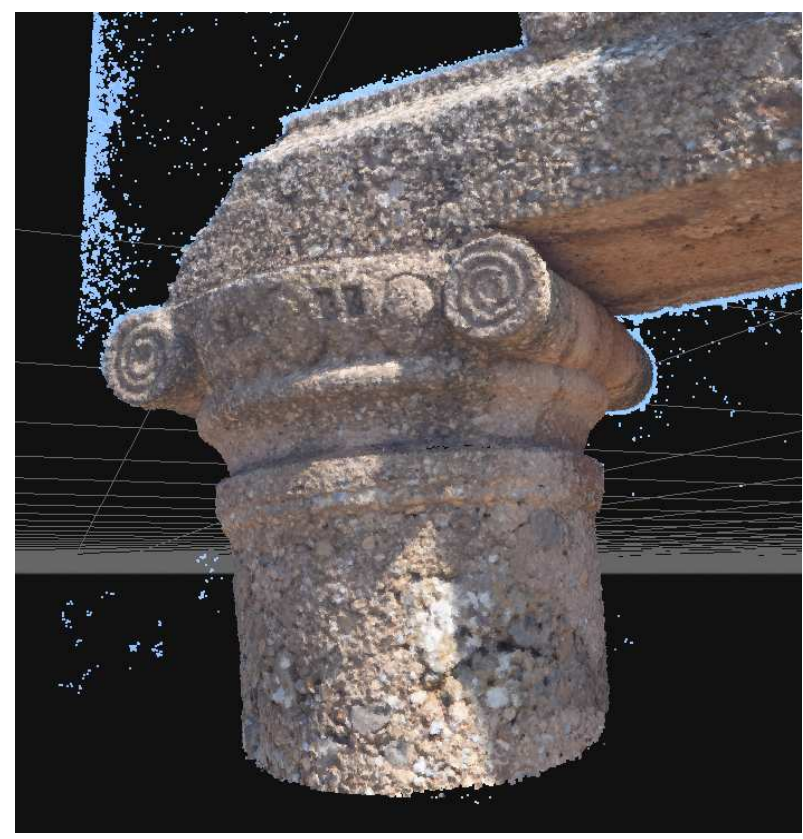

Figure 7. Dense point cloud of a capital from the Temple of Antas 


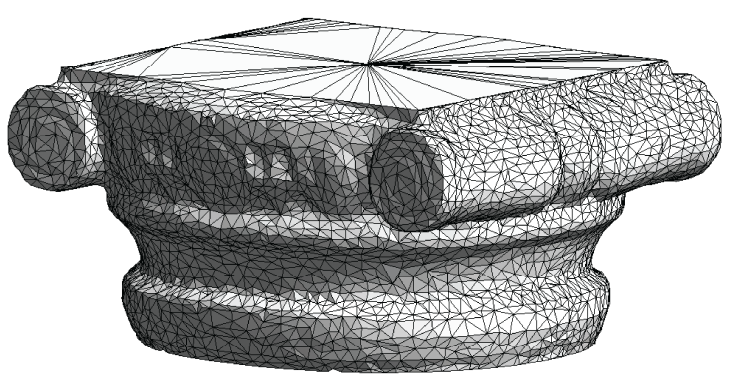

Figure 8. Mesh model of one of the Ionic capitals of the temple of Antas derived from the dense point cloud

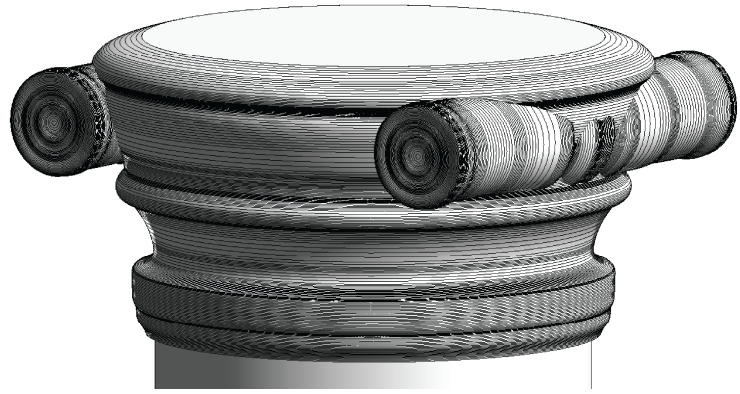

Figure 9. Parametric model of the capital generated by the profiles obtained from the dense point cloud

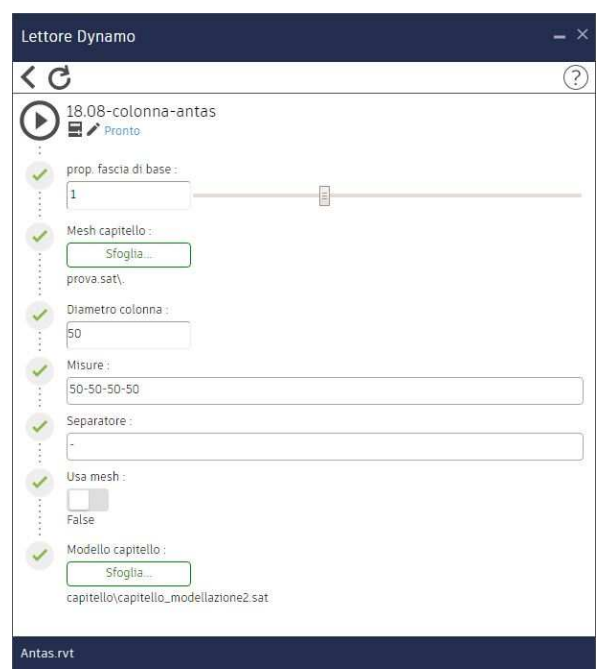

Figure 10. Dynamo player interface for entering the parameters by the user

The creation of the dense point cloud allowed us to create the different profiles, useful both to verify the proportions of the architectural order and to generate the parametric model relied on a fixed parameter set based on the decoding of the architectural order.

In order to optimize the modeling process, a specific algorithmic modeling of some elements has been carried out where necessary, as in the case of the temple colonnade.
The modeling of the column has provided for the articulation in its three different functional parts on each of which a different approach was applied: on the base, consisting of plinth and base proper, a standard parametrization was applied, typical of normal BIM processes; on the shaft it was necessary to use the algorithmic modeling to allow us to manage an indefinite quantity of variables; finally, the capital was treated both as a simple mesh surface and through parameterization on profiles.

The first elements taken into consideration were the bases of the columns, whose profiles have been obtained from the check of the measurements on the point clouds related to the proportions established in the historical treatises (Figure 6).

As historical reference documentation it was decided to use what Vignola described on the Doric order, which gave us a basis on which to base the study of the profile.

Once the proportions have been defined, the profile has been redesigned basing the shapes on the value of the diameter of the column, a parameter on which all the geometrical relations are set. The last step was to model the entire base through a revolution operation on the profile, whose only generator parameter is precisely the diameter of the column. In this way, a "basic" family can be scaled at any time.

In the first instance the shaft of the column can be traced back to a cylinder; it can be modelled starting from the measurements of its diameter and height, introducing the eventual entasis detected.

The normal parameterization process is not suitable for managing a variable number of parameters, making it difficult if not impossible to modify the number of drums to be created by the user according to the various measures. To overcome this problem, we used the algorithmic modeling that allowed us to set a procedure whereby given a string containing the various measures of the drums, this is segmented into a number of elements equal to how many measures are inserted and each segment is set as the height parameter in the extrusion that generates the drums. The result is an algorithm that starting from two parameters, base diameter and string of heights, can generate a shaft composed of $\mathrm{n}$ drums each of given size. Providing that each end user may have different needs as regards what character to use as a separator between the various heights, a third parameter has been used, which is precisely the character intended for the separator function.

Starting from the capitals point cloud (Figure 7), two different methods were used for its reproduction. Given the generally complex nature of the capital element we were faced with the choice whether to return this element to a very high level of detail as in the mesh model, necessary for an overall representation effective, although more complicated management of the model, especially in terms of performance (Figure 8); another possibility is to model the capital by approximating the shapes based, as in the case of the Attic base, on profiles extracted from point clouds. This second method allows a slimmer management of the model, both in terms of size of the file and in generation time, but going to create a three-dimensional model with a relatively low detail, sufficient however for purposes such as the global representation of the temple, for static checks, etc. (Figure 9). The user can then choose whether to load a mesh surface, saved in the SAT format, or generate the capital from scratch using preset profiles, in both cases passing through a step of scaling according to the diameter of the column.

The union of these three elements is therefore a parametric column that from time to time is generated according to the data of the survey and which allows to represent all the columns that make up the front porch. 
Once we have modelled the first column of the temple of Antas, having to make changes to the model or generate new ones, simply restart the algorithms by changing the input parameters to get the new column.

It is also important to note that the three methods described can all be performed by means of the algorithmic modeling which, as conceived in Revit through Dynamo, provides a single parametric generation process starting from the data entered by the user in the appropriate interface forms (Figure 10).

The final model of the colonnade is expressed through the mentioned phases which, starting from the point cloud, lead to the different models of the single parts, articulated in parametric, algorithmic and polygonal model (Figures.11, 12, $13,14)$.
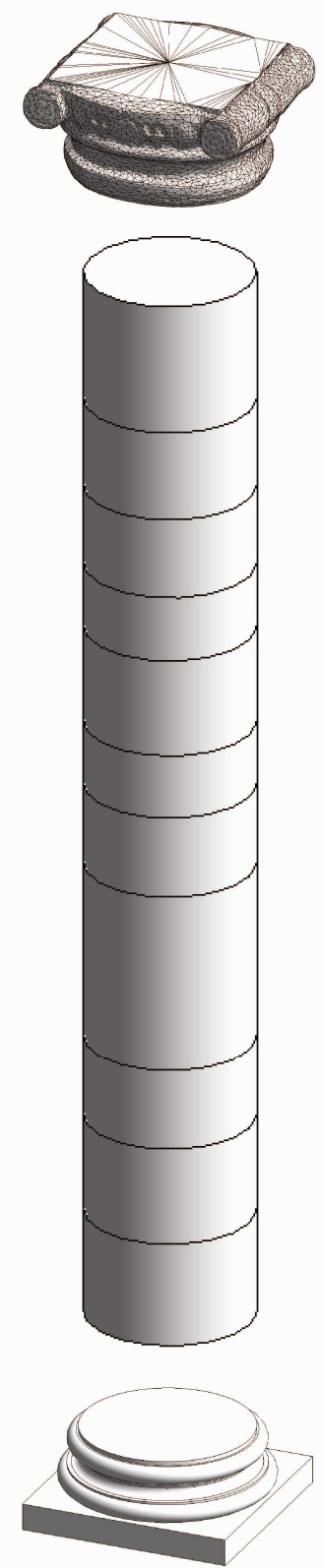

Figure 11. Starting from a partition in three segments, according to the vocabulary of the architectural orders, a first modeling of the column provided for a mesh modeling of the capital, an algorithmic modeling of the shaft and a parametric modeling for both the base and the plinth.

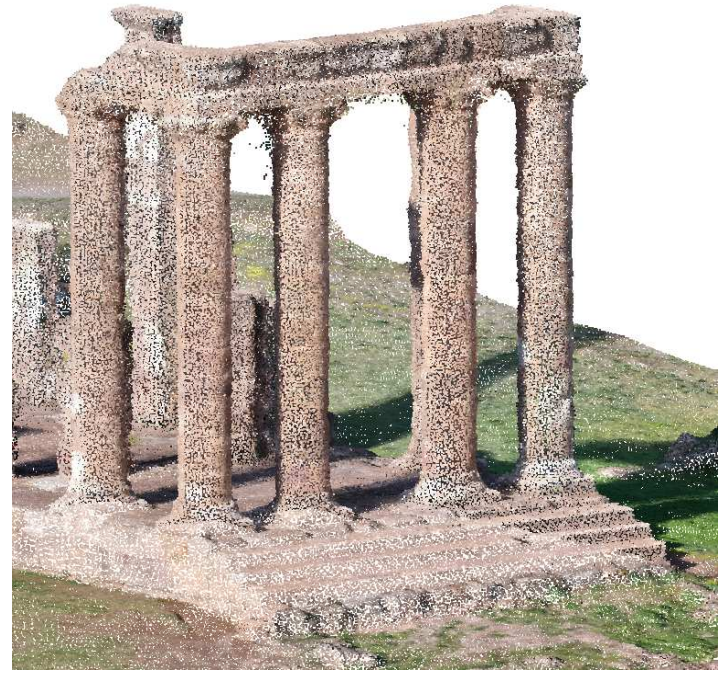

Figure 12. 3D point cloud model of the colonnade

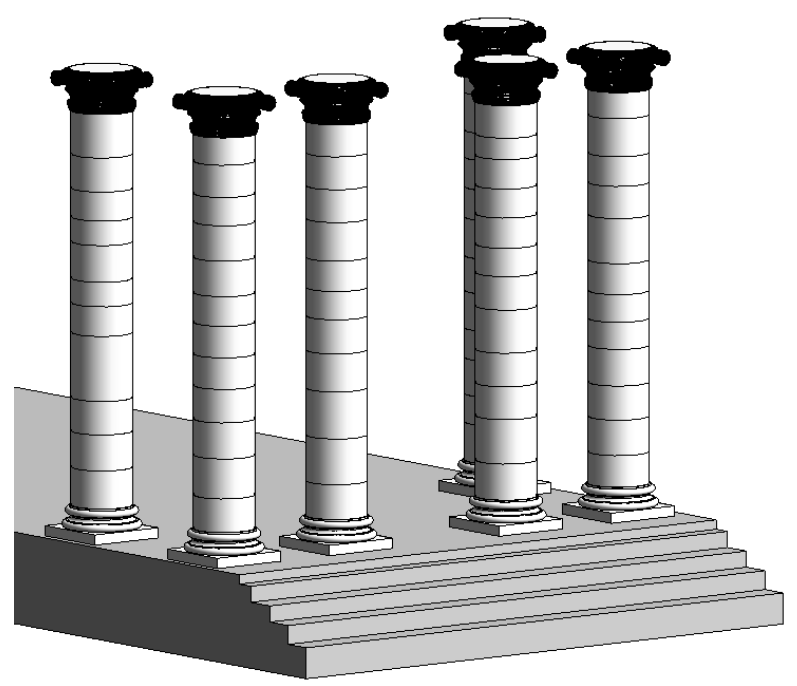

Figure 13. 3D model of the colonnade from the aggregation of the different modeling processes (parametric, algorithmic and polygonal modeling) identified with reference to the parts of the point cloud segmentation

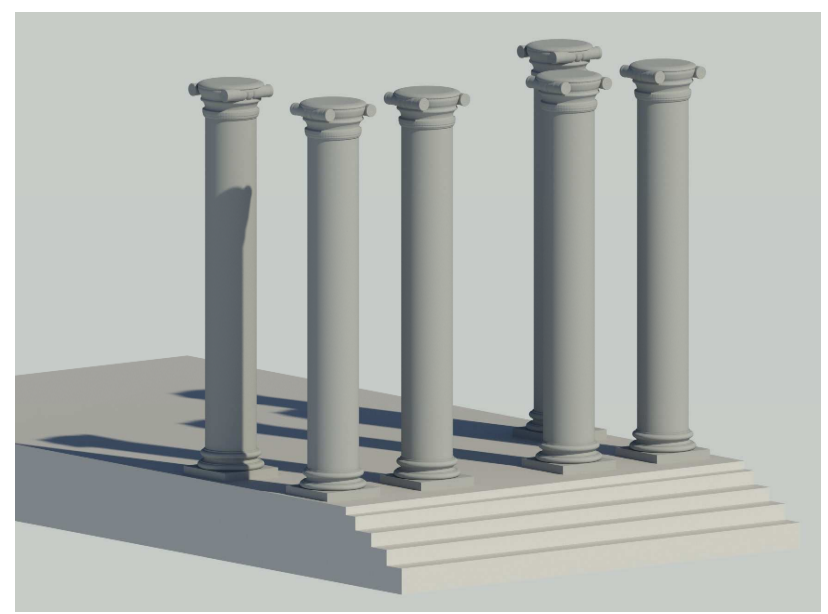

Figure 14. 3D conceptual rendering of the colonnade 


\section{CONCLUSIONS}

Thanks to the developments in data capture skills and software, archaeological data can now be easily integrated into BIM workflows. The transition from the architectural design area to the archaeological studies requires major investments especially with respect to the modeling processes. Starting from survey data, the foundation of a novel library of reusable objects takes advantage of procedural modeling processes creating 3D models specifically designed for historical architecture and archaeological sites.

Algorithmic modeling takes action in the process of geometric modeling where the gaps of parametric modeling or the complexity of objects generated from local modeling do not allow a streamlined and effective workflow in the BIM environment.

The future developments of the research aim in the next phase to the study of the reconstruction hypothesis realized in the restoration of the colonnade, referring to two main issues: the test of the consistency of the hypotheses advanced in the restoration and in the anastylosis with respect to the codification of the treatises of the architectural orders, and the visualization of the different levels of integrity of each single element.

The virtual reconstruction of the temple will be made in order to develop, as well as a simulation of the reconstructive hypothesis of the monument, an effective basis for the comparison and sharing of information between the different disciplines involved in the process of knowledge.

\section{ACKNOWLEDGEMENTS}

The authors wish to acknowledge Dr. Massimo Casagrande of the Superintendence of Archeology, Fine Arts and Landscape for the metropolitan city of Cagliari and the provinces of Oristano and South Sardinia, for his availability and scientific advice, and the staff of the START-ONE cooperative of Fluminimaggiore (SU), for the accessibility and welcome to the site of Antas.

\section{REFERENCES}

Apollonio F., Gaiani M., Zheng S., 2012. BIM-Based MOdeling and Data Enrichment of Classical Architectural Building. Sciret-It, Vol 3 Issue 2 (2012), pp. 41-62.

Barreca, F., 1975. Il tempio di Antas e il culto del Sardus Pater. Iglesias: Associazione Culturale Lao Silesu.

Barreca, F., 1985. Recenti scoperte in Sardegna. 2. Fluminimaggiore (Cagliari), Nuove scoperte ad Antas. In Rivista di Studi Fenici, 13, pp. 265-267.

Bartzis, D., 2017. Towards reconstructing a doric column in a virtual construction site. ISPRS - International Archives of the Photogrammetry, Remote Sensing and Spatial Information Sciences, XLII-2/W3, pp.91-96.

Bernardini P. and Ibba A., 2015. Il santuario di Antas fra Cartagine e Roma. In: "Sacrum nexum": alianzas entre el poder político y la religión en el mundo romano, Editors: J. Cabrero Piquero, L. Montecchio, pp.75-138.

Della Marmora, A., 1840. Voyage en Sardaigne ou Description statistique, physique et politique de cette ile, avec des recherches sur ses productions naturelles, et ses antiquités. Paris: Bertrand; Turin: Bocca.

Garagnani, S., Gaucci, A. and Govi, E., 2016a. ArchaeoBIM: Dallo scavo al Building Information Modeling di una struttura sepolta. Il caso del tempio tuscanico di Uni a Marzabotto. Archeologia e Calcolatori, 27, 251-270.

Garagnani, S., Gaucci, A., and Gruška, B., 2016b. From the archaeological record to archaeobim: the case study of the Etruscan temple of Uni in Marzabotto. Virtual Archaeology Review, 7(15), p.77.

Chiabrando, F., Lo Turco, M., and Santagati, C., 2017. Digital invasions: from point clouds to historical building object modeling (h-bom) of a unesco Whl site. ISPRS - International Archives of the Photogrammetry, Remote Sensing and Spatial Information Sciences, XLII-2/W3, pp.171-178.

Ganga S., Gavini A. and Sechi M., 2013. Nuove tecnologie applicate alla ricerca epigrafica: alcuni esempi, in "L'Africa Romana. Momenti di continuità e rottura: bilancio di 30 anni de L'Africa Romana", Atti del XX Convegno internazionale di Studi, AlgheroPorto Conte Ricerche 26-29 settembre 2013.

Grilli, E., Menna, F. and Remondino, F. 2017. A review of point clouds segmentation and classification algorithms. ISPRS - International Archives of the Photogrammetry, Remote Sensing and Spatial Information Sciences, XLII-2/W3, pp.339344.

Migliari R., 1991. Il disegno degli ordini e il rilievo dell'architettura classica: Cinque Pezzi Facili. Disegnare idee immagini, n. 2, Roma, 49-65.

Parello, G., Imperadori, M., Bennardo, C., Liotta, S-J. A., Ito, Y. and Vanossi, A., 2014. BIM for archaeology. Use of BIM process and parametric model in a temporary shelter adaptable to the diverse needs of archaeological sites. Proceedings of the International Conference: Preventive and Planned Conservation, Monza, Mantova: Politecnico di Milano e Nardini Editore.

Remondino, F., Spera, M.G., Nocerino, E., Menna, F., and Nex, F., 2014. State of the art in high density image matching. The Photogrammetric Record, 29: 144-166.

Santagati, C. and Lo Turco, M., 2016. 'From structure from motion to historical building information modeling: populating a semantic-aware library of architectural elements', Journal of Electronic Imaging. International Society for Optics and Photonics, 26(1), pp. 937-943.

Simeone, D., Cursi, S., Toldo, I., and Carrara, G., 2014. BIM and knowledge management for building heritage. In: Acadia (Vol. 2014, pp. 681-690).

Zucca R., 1989. Il tempio di Antas, collana "Sardegna archeologica. Guide e Itinerari”. Sassari: Carlo Delfino Editore. 